\title{
Vadesiz Mevduat Tutumu İçin Para Talebi Fonksiyonunun Tahmin Edilmesi
}

\author{
Levent KORALP*
}

\begin{abstract}
$\ddot{O} Z$
Bu çalışmada vadesiz mevduat tutumu için bir reel para talebi fonksiyonu çağdaş ardışık bağlanımlı gecikmesi dağıtılmış sınır testiyle tahmin edilmektedir. Para talebinin reel gelir esnekliği 1.92 olarak bulunmuş, reel gelir ve reel parasal büyüklükler arasındaki ilișkinin talep koșullarını paranın dolanım hızının tersi aracılığıyla etkileyeceği vurgulanmıştır. Reel para talebinin faiz yarıesnekliği ve enflasyon yarl-esnekliği strasiyla -0.41 ve -0.56 şeklinde elde edilmis, bu bulgu da iktisadi birimlerin dar kapsaml parasal tutumların belirlerken faiz oranını ve enflasyon oranını önemli bir alternatif maliyet olarak kabul etmelerine atfedilmiştir. Hata düzeltme modellemesi ile uzun dönem para talebi ilişkisinden sapmalarının \%16'sının bir dönem içerisinde ortadan kalktı̆̆g, yaklaşık altı dönem içerisinde para piyasası denge koşullarının yeniden sağlandığı anlaşılmıştır. Bu bulgular izlenerek para politikası tasarlanma ve uygulama sürecinde dar kapsaml parasal büyüklüklere ve bu büyüklükler arasındaki kuramsal temelli ilişkilere ait tahmin edilen bilginin politika yapıcılar açısından dikkate alınması gerektiği ve Türkiye ekonomisi açısından bu bilginin özellikle enflasyonist yapı ile iliş̧ilendirilmesi gerekliği şeklinde bir iktisat politikası çıkarsamasına ulaşılmıştır.
\end{abstract}

Anahtar Kelimeler: Para Talebi; Vadesiz Mevduatlar; Sinır Testi;

JEL Sinıflandırması: C32; E41; E52;

\section{Estimating Money Demand Function for Holding Demand Deposits}

\begin{abstract}
In this paper, a real money demand function for demand deposits is tried to be estimated by using contemporaneous autoregressive distributed lag bounds testing approach. The real income elasticity for money demand has been found as 1.92, which is related to that the relationship between real income and real money balances tends to affect the demand conditions through the inverse of the monetary velocity of circulation. Interest semi-elasticity and inflation semi-elasticity of real money demand have been obtained as -0.41 and -0.56 , respectively, which are also attributed to that economic agents accept the interest rate and inflation rate as an important alternative cost when determining the narrowly defined monetary holdings. The error correction modeling indicates that divergence from the long run money demand relationship is corrected $16 \%$ in one period, that is, equilibrium conditions are re-established within about six periods. Following these findings, in designing and implementation process of monetary policy, the estimated knowledge as for the narrowly defined monetary aggregates and the theory based relationships between these aggregates must be considered crucially by the policy makers and this knowledge must especially be related to the inflationary framework within the Turkish economy as a policy inference.
\end{abstract}

Keywords: Money Demand; Demand Deposits; Bounds Testing;

JEL Classification: C32; E41; E52;

\footnotetext{
* Doç.Dr. Kastamonu Üniversitesi İİBF İktisat Bölümü, Kuzeykent, Kastamonu, lkorap@ hotmail.com 


\section{GİRIŞ}

İktisadi bireylerin para tutumu şeklindeki davranışsal özelliklerinin incelenmesi para politikalarının değerlendirilme sürecinde önemli bir bilgi içeriğini açığa çıkarmaktadır. Bu tür bir araştırma hem kuramsal temelli makro iktisadi yaklaşımların geçerliliğinin sınanmasında hem de politika yapıcılar açısından politika yapım sürecinin tasarlanabilmesinde oldukça faydalı bir işlev görmektedir. Friedman (1977) tarafından vurgulandığı gibi talep edilen para miktarının doğru bir şekilde belirlenmesi parasal büyüklükleri elde bulundurmanın bireylere sağladığı getirilerin ve yüklediği maliyetlerin anlaşılmasını sağlamaktadır. Benzer şekilde, saptanan para politikası hedeflerine ulaşmak için uygun politika araçlarının seçilmesi, bireylerin mevcut para tutumlarına alternatif oluşturan maliyetlerin istatistiksel olarak anlamlı bir şekilde ortaya konulması ve tahmin edilen ilişkilerin istikrarlılığına yönelik yapılan çıkarsamalar parasal içerikli istikrar politikalarının taşıması gereken özellikler hakkında araştırmacıların çıkarsama yapmalarını olanaklı kılmaktadır (Favero, 2001). Bu değerlendirmelerin fonksiyonel bir yapı altında çağdaş bir tahmin sürecine dayandırılabilmesi iktisadi birimlere parasal yetkililerin saptadıkları hedefler ile politika gerçekleşmelerinin ne ölçüde uyum sağladığını belirleyebilme olanağ1 sunmaktadır (Goldfeld ve Sichel, 1990). Tahmin edilen fonksiyonel ilişkilerin istikrarsı bir yapı taşıması ele alınan örneklem dönemleri kapsamında yapısal bazı değişikliklere işaret edebilmekte, bu durum da uygulamalı modelleme yaklaşımları açısından geçersiz politika önerilerine yönelik eksik ya da yanlış bazı bulgulara ulaşıldığını gösterebilmektedir (Laidler, 1993).

İstikrarlı bir para talebi ilişkisinin ekonomiler açısından önemi bizler açısından veriyken, çeşitli ülke ve bölge örneklerini dikkate alan ve 2000'li yıllar sonrasında gerçekleştirilen Cakan ve Özmen (2002), Civcir (2003), Ramachandran (2004), Altınkemer (2004), Bahmani-Oskooee ve Rehman (2005), Bahmani-Oskooee ve Karacal (2006), Dreger ve devam1 (2007), Lee ve Chien (2008), Kim ve Subramanian (2009), Jawadi ve Sousa (2013) ve Davis ve devamı (2013) gibi pek çok yerli ve yabancı kaynaklı çalışmaya iktisat yazını içerisinde rastlanabilmektedir. Kendi çalışmamızda bu tür bir ilgi alanına katkı sağlamak amaciyla Türkiye ekonomisi verilerini kullanan ve bireylerin vadesiz mevduat tutumuna yönelik talebini modellemeye çalışan bir tahmin sürecinin gerçekleştirilmesi amaçlanmaktadır. Dolayısıyla daha çok işlem güdüsüyle bireylerin parasal tutum davranışları incelenmektedir. Çalışmamızın taslağı şu şekilde özetlenebilir. Bir sonraki bölümde veri tanımları ve zaman serisi özellikleri verilmekte, dikkate alınan fonksiyonel ilişki içsel kırılmayı dikkate alan birim kök sinamaları ile birlikte okuyucuya aktarılmaktadır. Daha sonra tahmin amacıyla kullanılan yöntemsel yaklaşım başlıca özellikleriyle tanıtılmakta ve izleyen bölümde de tahmin bulgularına yer verilmektedir. Çalışmaya yönelik bir özet sunum ile çalışma sonlandırılmaktadır. 


\section{I.VERI TANIMLARI}

Çalışmamızda dar tanımlı bir para talebi fonksiyonunun Türkiye ekonomisi için tahmin edilmesi amaçlanmaktadır. Bu şekilde iktisadi bireylerin daha çok işlem güdüsüyle parasal tutum davranışları incelenmektedir. Üçer aylık gözlem aralığını kullanan örneklem dönemi 2005Q4 - 2018Q2 olarak belirlenmiştir. Başlangıç döneminin 2005Q4 olarak belirlenmesinin nedeni bu tarihten itibaren Türkiye Cumhuriyet Merkez Bankası (TCMB) tarafından para arzı tanımlarında değişikliğe gidilerek para arzı tanımlarının bankacılık sistemindeki yerli para cinsinden mevduatlar ile yabancı para birimi cinsinden mevduatların yerli para birimi cinsinden değerinin toplamı şeklinde hesaplanmaya başlanmasıdır.

Çalışmada dar kapsamlı parasal büyüklük olarak tanımlanan $(m)$ değişkeni M1 para arzı büyüklüğünden dolaşımdaki para miktarının çıkarılması ile elde edilmekte ve bankacillk sistemindeki vadesiz mevduat hacmini dikkate almaktadır. İktisadi bireylerin para aldanmasına uğramadığı şeklindeki varsayım altında, para talebi reel parasal büyüklüklere bir talep şeklinde algılanmakta, reel parasal büyüklükleri elde etmek için ise cari fiyatlarla gayri safi yurt içi hasılanın (GSYIH) 2009: 100 temelli zincirleme hacim endeks yöntemine göre hesaplanan reel GSYIH'ye oranı şeklinde elde edilen GSYIH deflatörü kullanılmaktadır.

İktisadi bireylerin ellerinde tutmak isteyecekleri para miktarının bir belirleyicisi şeklinde reel gelir $(y)$ değişkeni olarak 2009: 100 temelli reel GSYİH dikkate alınmıştır. Elde para tutumunun alternatif maliyeti ise Hazine Müsteşarlığı aylık iç borçlanma ortalama bileşik faizi dönem ortalaması (i) ve GSYİH deflatöründeki bir dönemlik yüzde değişim şeklinde hesaplanan üç aylık enflasyon $(\pi)$ oranı ile temsil edilmiştir.

Dar kapsamlı parasal büyüklük tutumu için kendi getiri oranı basitlik açısından sıfır olarak kabul edilmiş ve modellemeye sokulmamıştır. Reel parasal büyüklük ve reel gelir için doğal logaritma alma işlemcisi kullanılmış olup elde para tutumuna yönelik alternatif bir maliyet olarak dikkate alınan faiz oranı ve enflasyon oranı değişkeni için yarı-logaritmik bir yapıda bu değerler zaten oran şeklindeki birer büyüklük olarak model sokuldukları için böyle bir dönüşüm gerçekleştirilmemiştir.

Çalışmada kullanılan bütün veriler mevsimsellikten arındırılmamış bir yapıda modele sokulmuş olup reel parasal büyüklük, reel gelir ve enflasyon hesaplamasında kullanılan veriler TCMB elektronik veri dağıtım sisteminden (https://evds2.tcmb.gov.tr, erişim tarihi: 28.01.2019) ve faiz oranı verileri T.C. Cumhurbaşkanlığı Strateji ve Bütçe Başkanlığı elektronik veri dağıtım sisteminden (https://www.sbb.gov.tr/, erişim tarihi: 28.01.2019) derlenmiştir.

Model tahminine geçilmeden önce değişkenlerin birim kök bilgisi incelenmektedir. Bu amaçla Lee ve Strazicich (2003) tarafından önerilen ve sınama sürecinde içsel kırılmaların varlığına izin veren birim kök sınama yöntemine başvurulmuştur. Kırılma altında birim kökün varlığı $H_{0}$ varsayımına dayalı sınama sonuçları Tablo 1'de aktarılmaktadır: 
Tablo 1. Lee-Strazicich (2003) birim kök sınaması: İki içsel kırılma

\begin{tabular}{|c|c|c|c|}
\hline Değişkenler & Model: Crash & Model: Break & Çıkarsama \\
\hline$m_{t}$ & $-2.39(09 \mathrm{Q} 4,12 \mathrm{Q} 3)$ & $-5.49(07 \mathrm{Q} 4,12 \mathrm{Q} 4)$ & $I(1)$ \\
\hline$\Delta m_{t}$ & $-3.68(11 \mathrm{Q} 3,15 \mathrm{Q} 3)$ & $-7.80(08 \mathrm{Q} 1,09 \mathrm{Q} 2)$ & $I(0)$ \\
\hline$y_{t}$ & $-3.79(07 \mathrm{Q} 4,11 \mathrm{Q} 2)$ & $-6.06(08 \mathrm{Q} 2,12 \mathrm{Q} 4)$ & $I(0)$ ya da $I(1)$ \\
\hline$\Delta y_{t}$ & $-3.88(15 \mathrm{Q} 2,16 \mathrm{Q} 4)$ & $-7.58(08 \mathrm{Q} 3,11 \mathrm{Q} 4)$ & $I(0)$ \\
\hline$i_{t}$ & $-2.69(08 \mathrm{Q} 4,09 \mathrm{Q} 3)$ & $-7.45(09 \mathrm{Q} 2,13 \mathrm{Q} 3)$ & $I(0)$ ya da $I(1)$ \\
\hline$\Delta i_{t}$ & $-6.33(09 \mathrm{Q} 2,14 \mathrm{Q} 3)$ & $-6.82(08 \mathrm{Q} 1,09 \mathrm{Q} 4)$ & $I(0)$ \\
\hline$\pi_{t}$ & $-5.11(08 \mathrm{Q} 2,11 \mathrm{Q} 4)$ & $-10.58(08 \mathrm{Q} 2,15 \mathrm{Q} 2)$ & $I(0)$ \\
\hline$\Delta \pi_{t}$ & $-6.85(07 \mathrm{Q} 4,10 \mathrm{Q} 2)$ & $-11.83(07 \mathrm{Q} 4,09 \mathrm{Q} 3)$ & $I(0)$ \\
\hline Kritik değer & $\% 5$ & -3.56 & -6.18 \\
\hline
\end{tabular}

Yukarıda $\Delta$ fark işlemcisidir. Tablo iki olası çoklu kırılma altında LeeStrazicich (2003) en küçük sınama istatistiklerini (tau) sunmaktadır. Tahmin bulguları, seçilen örneklem içerisindeki bilinmeyen bir tarihte yapısal kırılmayı dikkate almaktadır. Olası kırılma tarihleri parantez içerisinde belirtilmiştir. Sınamalar için dikkate alınan en yüksek gecikme uzunluğu 5 olarak saptanmıştır. Birim kök tahmin bulgularına göre düzey değerleri itibariyle reel parasal büyüklükler $I(1)$ ya da birinci dereceden bütünleşik bir yapıda bulunurken ölçek reel gelir değişkeninin ve elde para tutumunun alternatif maliyeti şeklindeki faiz oranı değişkeninin kullanılan birim kök modeline göre düzey değerleri açısından $I(0)$ ya da $I(1)$ olma durumu çelişkili bir sonuç üretmektedir. Enflasyon oranı ise düzey değerler açısından durağan bir yapıda bulunmuştur. Bu bulgular doğrultusunda modelin tahmin için çağdaş bir zaman serisi tahmin yöntemi olan ardışık bağlanımlı gecikmesi dağıtılmış sınır testine başvurulmaktadır.

\section{ARDIŞIK BAĞLANIMLI GECİKMESİ DAĞITILMIŞ $(A R D L)$ SINIR TESTI YAKLAŞIMI}

Kullanılan değişkenlerin farklı bütünleşme derecesine sahip olması nedeniyle tek denklemli Engle ve Granger (1987) yöntemi ya da bir vektör ardış1k bağlanım $(V A R)$ yapısı altında en çok olabilirlik temelli Johansen (1995) çok değişkenli eşbütünleşim yöntemi dikkate aldığımız veri yapısına uygun düşmemektedir (Göktaş, 2005). Pesaran, Shin ve Smith (2001) tarafından önerilen $A R D L$ sınır testi yaklaşımıysa $I(0)$ ya da $I(1)$ değişkenlerin birlikte bir eşbütünleşik değişken uzayında bulunmalarına izin vermektedir. Bu doğrultuda aşağıdaki vektör hata düzeltme modelini ele alalım: 


$$
\Delta Y_{t}=\mu+\lambda Y_{t-1}+\sum_{j=1}^{p-1} \gamma_{j} \Delta Y_{t-j}+\varepsilon_{t}
$$

Yukarıda $Y_{t}=\left[y_{t} x_{t}\right]^{\prime}$ şeklinde tanımlanan değişken vektörüdür. $\mu=\left[\mu_{y} \mu_{x}\right]^{\prime}$ sabit katsayı vektörü ve $\Delta=(1-L)$ fark işlemcisini göstermektedir. $\varepsilon_{t}=\left[\varepsilon_{y} \varepsilon_{x}\right]^{\prime} \sim N(0, \Omega)$ hata terimleri vektörünün normal bir dağılıma sahip, sıfır ortalama değerli ve sabit varyanslı olduğu varsayılmaktadır. $\lambda$ uzun dönemli çarpan matrisini ve $\gamma$ kısa dönemli tepki matrisini göstermektedir:

$$
\begin{aligned}
& \lambda=\left[\begin{array}{l}
\lambda_{y y} \lambda_{y x} \\
\lambda_{x y} \lambda_{x x}
\end{array}\right]=-\left(I-\sum_{j=1}^{p} \phi_{j}\right) \\
& \gamma_{j}=\left[\begin{array}{l}
\gamma_{y y, j} \gamma_{y x, j} \\
\gamma_{x y, j} \gamma_{x x, j}
\end{array}\right]=-\sum_{k=j+1}^{p} \phi_{k}
\end{aligned}
$$

$I$ birim matrisi ve $\phi_{j}$ vektör ardışı bağlanım katsayı matrisidir. $\lambda$ matrisinin köşegen elemanlarının sınırlandırılmaması zaman serilerinin $I(0)$ ya da $I(1)$ olmasına olanak sağlamaktadır. Örneğin $\lambda_{y y}=0$ ifadesi $y$ değişkeninin $I(1)$ ve $\lambda_{y y}<0$ ifadesi değişkenin $I(0)$ olmasını ifade etmektedir. Uzun dönem çarpan matrisinin köşegen dışı elemanlarından biri, $\lambda_{y x}$ ya da $\lambda_{x y}$, sıfır değerini alabilmektedir. Bu yaklaşım ile tek denklemli eşbütünleşik bir ilişki değişkenlerin $I(0)$ ya da $I(1)$ olmalarına aldırış edilmeksizin tahmin edilebilmektedir:

$$
\Delta y_{t}=\alpha+\varphi y_{t-1}+\delta x_{t-1}+\omega \Delta x_{t}+\sum_{j=1}^{p-1} \beta_{p, j} \Delta y_{t-j}+\sum_{j=1}^{q-1} \beta_{x, j} \Delta x_{t-j}+u_{t}(4)
$$

(4) no'lu eşitlikte $\varphi$ ve $\delta$ uzun dönem çarpan katsayılarını ve $\Delta y_{t-j}$ ve $\Delta x_{t-j}$ hata düzeltme modelinin kısa dönem dinamik yapısını göstermektedir. Sınır testi yaklaşımı (4) no'lu eşitliğin trend bileşenini içeren veya içermeyen bir şekilde en küçük kareler $(O L S)$ yöntemiyle tahmin edilmesini gerektirmekte ve aşağıdaki varsayımlar doğrultusunda $F$ - istatistikleri yardımıyla $y_{t}$ ve $x_{t}$ değişkenlerinin düzey değerleri arasında uzun dönemli olası bir ilişkinin varlığını ortaya koymaktadır:

$$
\begin{aligned}
& H_{0}: \varphi=0, \delta=0 \\
& H_{1}: \varphi \neq 0, \delta \neq 0
\end{aligned}
$$


(5) no'lu eşitlikte $F$ - ya da Wald - sınamaları ile $H_{0}$ hipotezinin reddedilmesi $H_{1}$ hipotezinin kabul edilmesine yol açacak ve kullanılan değiş̧enler arasındaki uzun dönemli bir denge ilişkisini gösterecektir. Tahmin edilen istatistikler Pesaran ve devamı (2001) çalışmasında aktarılan ve standart olmayan bir dağılıma sahip ölçüt değerlerin kavuşmazda sahip olması gereken değerlerle karşılaştırılmaktadır.

Hesaplanan $F$ - istatistiğinin eşik değerleri ifade eden sınırların dışına düşmesi durumunda, değişkenlerin $I(0)$ ya da $I(1)$ şeklinde bütünleşme derecelerini bilmeye gerek kalmaksızın değişkenlerin düzey değerleri arasında eşbütünleşik bir ilişkinin bulunması durumu kesin olarak belirlenebilmektedir. Bu durumda $F$ - istatistiğinin üst eşik sınır değerinin üzerinde tahmin edilmesi değişkenler arasında eşbütünleşik bir ilişkinin bulunmadığı $H_{0}$ varsayımının reddedilmesine yol açmakta, $F$ - istatistiğinin alt eşik sınır değerinden düşük bulunmasıysa $H_{1}$ almaşı varsayımının kabul edildiğini ve bu doğrultuda değişkenler arasındaki olası eşbütünleşik bir ilişki durumunun bulunmadığını göstermektedir.Hesaplanan $F-$ istatistiğinin dikkate alınan eşik sınır değerlerinin arasına düşmesi durumundaysa, değişkenler arasındaki olası bir eşbütünleşik ilişkinin varlığıyla ilgili olarak değişkenlerin bütünleşme derecelerinin bilinmesi gerekmektedir.

$\mathrm{Bu}$ tahmin sürecinin yanı sıra (4) no'lu eşitlikte bir dönem gecikmeli bağımlı değişken katsayısının $t$-istatistiğinin Pesaran ve devamı (2001) çalışması içerisinde aktarılan eşik değerleri aşması da modeldeki değişkenler arasında eşbütünleşik bir ilişkinin varlığını gösterebilecektir. $A R D L$ temelli sınır testi yaklaşımı küçük örneklem kullanımında dahi tutarlı uzun dönem katsayı tahmincileri üretebilmektedir.

\section{SINIR TESTI TAHMIN BULGULARI}

Bir sonraki aşamada para talebi denklemine yönelik elde edilen tahmin içerikli sonuçların tutarlıı̆̆ğnı sınayabilmek için Pesaran vde devamı (2001) çalışması tarafından önerilen çağdaş $A R D L$ eşbütünleşim denklemi ve bu denklem kullanılarak türetilen hata düzeltme modeli tahmin edilmeye çalışılmıştır. $\mathrm{Bu}$ amaçla $A R D L$ modelinde dikkate alınan bağımlı değişken ve açıklayıcı değişkenler için gecikme sayısı en çok 4 olarak dikkate alınmak üzere Akaike bilgi ölçütü $(A I C)$ kullanılarak pek çok $A R D L$ modeli bulunmuştur. Belirtilmelidir ki, tahmin edilen model sayıs1 500'dür.

Herhangi bir deterministik bileşenin dikkate alınmaması ya da deterministik bileşen olarak yalnız sabit katsayının dikkate alınması durumunda $\operatorname{ARDL}(4,1,0,0)$ modeli ve deterministik bileşen olarak sabit katsayı ve trendin birlikte dikkate alınması durumunda $\operatorname{ARDL}(3,0,0,2)$ modeli bilgi ölçütünü en küçük yapan uygun model olarak saptanmaktadır. Eşbütünleşik yani durağan 
yapıdaki olası bir iktisadi ilişkinin varlığı dikkate alınan deterministik bileşen varsayımlarına bağlı olarak Tablo 2 içerisinde sunulmaktadır. Tahmin edilen olasıllk değerlerine ilişkin standart hatalar Pesaran ve Shin (1998) izlenerek delta yöntemiyle elde edilmiştir. Sınır testi $F$ - istatistiği $I_{0}$ ve $I_{1}$ kritik değerleri için \%5 anlamlılık düzeyi dikkate alınmıştır. Değişken olasılık değerleri [ ] içerisinde belirtilmiştir.

Uzun dönem düzey değer eşitliklerinin incelenmesi eşitliğe kısıtlanan deterministik bileşen varsayımlarından bağımsız olarak tahmin edilen bütün modeller için değişkenler arasında eşbütünleşik bir ilişki olduğunu ortaya koymaktadır. Tüm modellerde $F$-Sınır testi $F$-istatistiği $I(0)$ ve $I(1)$ eşik sınır değerlerinin üzerinde bulunmaktadır. Ayrıca sabit katsayı ya da trend bileşeninin koşullu hata düzeltme modelinde yer almasına karşıllk uzun dönem düzey değer eşitliğine kısıtlanmadığ 1 modellerde $t$-Sinır testi $t$-istatistiği de mutlak değer olarak eşik sınır değerlerinin üzerinde bir sonuç vermektedir. Modeller genel olarak benzer değişken katsayı bulguları üretmektedir. Bütün modeller içerisinde deterministik bileşenler açısından yalnız sabit terimin koşullu hata düzeltme modelinde yer aldığı ve uzun dönem düzey değer eşitliğine kısıtlandığ1 'kısıtlanmış sabit \& trend yok' $\operatorname{ARDL}(4,1,0,0)$ modeli modeli en yüksek $F$-Sınır testi $F$-istatistiğine sahip model durumundadır. İzleyen bölümde bu model ile çözümlemeye devam edilecektir. Tahmin edilen eşitlik Tablo 2'de aktarılmıştır.

(6) no'lu eşitlikte elde edilen bütün katsayılar istatistiksel anlamlılığa sahip olarak gözükmektedir. Yukarıda para piyasası denge koşulları altında tahmin ettiğimiz para talebine yönelik reel gelir esnekliği 1.92 olarak bulunmuştur. $\mathrm{Bu}$ noktada Sarno (1999) izlenerek reel gelir ve reel parasal büyüklükler arasındaki ilişkinin ekonomide mevcut talep koşullarını paranın dolanım hızının tersi aracılığıyla etkileyebileceği, dolayısıyla reel gelir esnekliği birim katsayısından büyük elde edildiği için reel parasal büyüklüklere yönelik talebin para piyasası denge koşullarının sağlandığı uzun dönemde paranın dolanım hızında bir azalma meydana getirecek şekilde iktisadi birimlerce sanki lüks mallara yönelik bir talep gibi algılanabileceği belirtilmelidir.

Reel para talebinin yarı-faiz esnekliği katsayısı -0.41 şeklinde tahmin edilmiştir. İktisadi birimler dar kapsamlı, yani işlem güdüsü içerikli parasal tutumlarını belirlerken faiz oranını önemli bir alternatif maliyet olarak kabul etmektedir. Faiz oranının devlet iç borçlanma senetleri ağırlıklandırılmış fazi oranı olduğu dikkate alındığında makroiktisadi ölçüde elde edilen bu bulgu finansal piyasalardaki gelişmelerin de bireylerce yakından takip edildiğini ortaya koymakta, finansal piyasaların gelişmişlik derecesi hakkında da bizlere reel para talebi kapsamında da olsa bir bilgi sunmaktadır.

Benzer şekilde enflasyon değişkeni de istatistiksel olarak anlamlı bir şekilde negatif işaretli olarak tahmin edilmiştir. Yurt içi enflasyondaki artışlar da elde para tutumuna alternatif bir maliyet oluşturmaktadır. Bu noktada, ekonomiye 
egemen enflasyonist yapı altında iktisadi bireylerin elde para tutumunu azaltarak mal ve hizmet tüketimlerini arttırma eğiliminde olacakları şeklinde bir çıkarsama yapılabilecektir. Bu modele ait tanı koyma (diagnostic) sınama bilgileri Tablo 3 içerisinde verilmiştir.

Tablo 2. Uzun dönem düzey değerler eşitliği ve sınır testi

Deterministik bileşenler

$\operatorname{ARDL}(4,1,0,0)$ modeli

Sabit yok \& trend yok

$$
\begin{gathered}
m_{t}=1.20 * y_{t}-0.25 * i_{t}-0.42 * \pi_{t} \\
{[0.02] \quad[0.05] \quad[0.06]}
\end{gathered}
$$

$F-$ Sinır testi

$$
\begin{array}{llll} 
& & I(0) & I(1) \\
F-\text { ist. } 7.89 & 5 \% & 2.45 & 3.63
\end{array}
$$

$t-$ Sinır testi

$$
t-i s t .-3.60 \quad 5 \% \quad-1.95 \quad-3.33
$$

$\operatorname{ARDL}(4,1,0,0)$ modeli

Kısıtlanmış sabit \& trend yok $\quad m_{t}=1.92 * y_{t}-0.41 * i_{t}-0.56 * \pi_{t}-18.49$

$$
[0.00] \quad[0.02] \quad[0.06] \quad[0.00]
$$

$F-$ Sinır testi

$$
\begin{array}{cccc} 
& & I(0) & I(1) \\
\text { F-ist. } 13.46 & 5 \% & 2.79 & 3.67
\end{array}
$$

$\operatorname{ARDL}(4,1,0,0)$ modeli

Kısıtlanmamış sabit \& trend yok $m_{t}=1.92 * y_{t}-0.41 * i_{t}-0.56 * \pi_{t}$

$$
[0.00] \quad[0.02] \quad[0.06]
$$

$F-$ Sinır testi

$t-$ Sinır testi

$$
t-i s t .-4.97 \quad 5 \% \quad-2.86 \quad-3.78
$$

$\operatorname{ARDL}(3,0,0,2)$ modeli

Kısıtlanmamış sabit \& kisıtlanmış trend $m_{t}=1.10 * y_{t}-0.41 * i_{t}-0.64 * \pi_{t}-0.01 *$ trend

$$
[0.00] \quad[0.05] \quad[0.00] \quad[0.00]
$$

$F-$ Sinır testi

$$
\begin{array}{cccc} 
& & I(0) & I(1) \\
F-\text { ist. } 11.20 & 5 \% & 3.38 & 4.23
\end{array}
$$

$\operatorname{ARDL}(3,0,0,2)$ modeli

Kısıtlanmamış sabit \& kısıtlanmamış trend $m_{t}=1.10 * y_{t}-0.41 * i_{t}-0.64 * \pi_{t}$

$$
[0.00] \quad[0.05] \quad[0.00]
$$

$F-$ Sinır testi

$$
\begin{array}{cccc} 
& & I(0) & I(1) \\
\text { F-ist. } 12.90 & 5 \% & 4.01 & 5.07
\end{array}
$$


$t-$ Sinir testi

$$
t-i s t .-3.92 \quad 5 \% \quad-3.41 \quad-4.16
$$

$$
\begin{gathered}
m_{t}=1.92 * y_{t}-0.41 * i_{t}-0.56 * \pi_{t}-18.49 \\
{[0.00] \quad[0.02] \quad[0.06] \quad[0.00]}
\end{gathered}
$$

Tablo 3. Tanı koyma (diagnostic) bilgileri

\begin{tabular}{lccc}
\hline$\chi_{S C}^{2}(1)$ & $\chi_{S C}^{2}(4)$ & Nor & Het \\
$0.11(0.74)$ & $0.50(0.73)$ & $1.08(0.58)$ & $0.68(0.72)$ \\
\hline
\end{tabular}

Yukarıda $\chi_{S C}^{2}(1)$ ve $\chi_{S C}^{2}(4)$ ardışı bağımlılık (serial correlation) olmaması sıfır varsayımı altında sırasıyla birinci ve dördüncü dereceden BreuschGodfrey hata terimleri Lagrange çarpanı testi $F$-istatistiklerini, Nor hata terimlerinin normal dağılımı sıfır varsayımı altında Jarque-Bera normallik istatistiğini ve Het sabit varyanslılık sıfır varsayımı altında Breusch-PaganGodfrey değişen varyans testi $F$-istatistiklerini göstermektedir. Test istatistiklerine ait olasılık değerleri parantez içerisinde gösterilmiştir. Tablo 3'ün incelenmesi $\operatorname{ARDL}(4,1,0,0)$ modeli açısından herhangi bir tanı koyma sorunu ortaya koymamakta ve elde edilen hata terimlerinin beyaz gürültü hata terimi olma özelliğine sahip olduğunu göstermektedir. $A R D L$ modeline ait kısa dönem hata düzeltme modeli istatistiksel olarak anlamlı bulunan değişken katsayılarıyla

\begin{tabular}{|c|c|c|c|c|}
\hline \multicolumn{5}{|c|}{ Bă̆ımlı değişken : $d(\text { er })_{t}$} \\
\hline Değişken & Katsayı & Std.Hata & $t-i s t$ & olas. \\
\hline$d(m)_{t-1}$ & -0.25 & 0.09 & -2.66 & 0.01 \\
\hline$d(m)_{t-3}$ & -0.24 & 0.09 & -2.76 & 0.01 \\
\hline$E C_{t-1}$ & -0.16 & 0.02 & -8.64 & 0.00 \\
\hline$C$ & 0.50 & 0.08 & 5.92 & 0.00 \\
\hline $\operatorname{Adj.} R^{2}$ & \multicolumn{2}{|c|}{0.64} & & \\
\hline Durbin & son stat & & & \\
\hline
\end{tabular}
birlikte Tablo 4 içerisinde sunulmaktadır:

Tablo 4. $A R D L(4,1,0,0)$ Modeline Ait Koşullu Hata Düzeltme Regresyonu

Tablo 4 göstermektedir ki uzun dönem durağan para talebi denge ilişkisinden sapmaların yaklaşık \%16'sı bir gözlem dönemi içerisinde ortadan kalkmaktadır. Diğer bir deyişle, tahmin edilen model doğrultusunda yaklaşık altı gözlem dönemi içerisinde para piyasası denge koşullarının yeniden sağlandığı anlaşılmaktadır. 


\section{SONUÇ}

Çalışmada Türk bankacilık sistemindeki vadesiz mevduatlar ile temsil edilen dar kapsamlı parasal büyüklüğe yönelik talebin belirleyicileri makro iktisadi içerikli işlevsel bir ilişki aracılı̆̆ıyla incelenmeye çalışılmıştır. Bu amaçla oluşturulan reel para talebi denklemi çağdaş ardışık bağlanımlı gecikmesi dağıtılmış $(A R D L)$ sınır testi yaklaşımı ile tahmin edilmiştir. Bütün değişkenler kabul edilebilir sınırlar içerisinde istatistiksel anlamlılığa sahip olarak bulunmuştur. Para talebine yönelik reel gelir esnekliği 1.92 olarak tahmin edilmiş, reel gelir ve reel parasal büyüklükler arasındaki ilişkinin ekonomide mevcut talep koşullarını paranın dolanım hızının tersi aracılığıyla etkileyebileceği vurgulanmıştır. Reel para talebinin faiz yarı-esnekliği katsayıs1 -0.41 ve enflasyon yarı-esnekliği katsayısı - 0.56 şeklinde elde edilmiş, bu bulgu iktisadi birimlerin dar kapsamlı parasal tutumlarını belirlerken faiz oranını ve enflasyon oranını önemli bir alternatif maliyet olarak kabul etmelerine atfedilmiştir. Gerçekleştirilen hata düzeltme modellemesi doğrultusunda uzun dönem durağan para talebi ilişkisinden sapmaların yaklaşık \% 16'sının bir dönem içerisinde ortadan kalktı̆̆ yani yaklaşık altı gözlem dönemi içerisinde para piyasası denge koşullarının yeniden sağlandığı anlaşılmıştır. Tahmin edilen modelde herhangi bir tanı koyma (diagnostic) sorunuyla karşılaşılmaması modelin istenen başlıca istatistiksel tutarlılık ölçütlerini yerine getirdiğini ortaya koymuştur.

Elde edilen bulgular Türkiye ekonomisi koşullarında ve örneklem döneminde bireylerin dar kapsamlı parasal tutumlarının belirleyici bileşenlerini ortaya koymaya yönelik tahminlerin iktisat politikası yapıcıları açısından gerçekleştirilebileceğini göstermektedir. Kullanılan ekonometrik tahmin yöntemi olan eşbütünleşim yöntemi doğrultusunda önsel iktisadi beklentiler ile uyumlu bulgular elde edilmesi bu duruma destek vermektedir. Bireylerin dar kapsamlı ya da işlem güdüsü açısından parasal tutumlarını etkileyen bileşenlerin istatistiksel tanı koyma sınamalarından da geçecek bir şekilde elde edilmesi para piyasası denge koşullarının tahmin edilebilmesini ve piyasa dengesizlik koşulları altında ortaya çıkacak arz ve talep fazlalarının saptanabilmesini olanaklı kılmaktadır. Böyle bir sonuç ise para piyasasından türetilen dengesizliklerin yurt içi enflasyon ve reel milli gelir büyüme süreci gibi başlıca makro iktisadi sorunlar ile ilişkilendirilebilmesini sağlayacaktır. $\mathrm{Bu}$ kapsamda para piyasası arz fazlalıklarının, örneğin Parasalcı ya da Monetarist iktisadi düşünce okulu kapsamında, yurt içinde enflasyonist bir baskıya yol açıp açmaması durumu kendi çalışmamızda elde ettiğimiz bulgulara paralel olarak tamamlayıcı bir çalışma şeklinde ortaya konulabilecektir.

Para piyasası denge koşullarının uygulamalı bir şekilde ekonomideki varlığının gösterilmesi para politikası yapıcılarının politika uygulama sürecinde dar kapsamlı parasal büyüklüklere yönelik istikrar politikası uygulamalarını destekler bir özellik göstermektedir. Ancak, çalışmamızda böyle bir uygulama yapılmış olsa dahi gerek örneklem döneminin yıl temelli olarak nispeten kısa olması gerekse de elde edilen eşbütünleşik ya da değişkenler arasındaki uzun 
dönemli durağan ilişkinin özellikle politika yapıcıların uyguladıkları politikalardaki farklılaşmalara bağlı olarak Türkiye ekonomisi koşullarında yapısal kırılmalara maruz kalmış olabilmesi durumu bu bulguların araştırmacılar ve diğer ilgililer açısından ihtiyatlı bir şekilde değerlendirilmesini gerekmektedir. $\mathrm{Bu}$ kapsamda çalışmamızda elde ettiğimiz işlevsel temelli tahmin bulguları açısından söz konusu yapısal farklılaşmaların ekonometri düşünce alanıdaki çağdaş gelişmelerin de 1şı̆̆ı altında incelenmesi bu bulguların tutarlılı̆̆ını sorgulamaya yönelik tamamlayıcı bir gelecek çalışma olacaktır. Dolayısıyla Türkiye ekonomisine yönelik ve özellikle para piyasası denge ilişkisinden sapmaların yurt içi enflasyon ile ilişkilendirildiği araştırma sürçlerinin bu çalışma izlenerek gerçekleştirilmesi gerekliliği düşünülmektedir.

\section{KAYNAKÇA}

Altınkemer, M. (2004). Importance of Base Money Even When Inflation Targeting, CBRT Research Department Working Paper 04/04.

Bahmani-Oskooee, M. and Rehman, H. (2005). Stability of the Money Demand Function in Asian Developing Countries, Applied Economics, 34, 2075-083.

Bahmani-Oskooee, M. and Karacal, M. (2006). The Demand for Money in Turkey and Currency Substitution, Applied Economics Letters, 13, 635-42.

Cakan, P. \& Özmen, E. (2002). Policy Regime Change and Structural Break in the Velocity of Money: The Turkish Evidence, Applied Economics Letters, 9, 759-62.

Civcir, I. (2003). Broad Money Demand, Financial Liberalization and Currency Substitution in Turkey, Journal of Economic Studies, 30(5), 514-34.

Davis, B., Karemera, D. and Whitesides, L. (2013). The Intertemporal Stability of the US Money Demand Function: New Evidence from Switching Regressions, Applied Economics Letters, 20(6), 581-86.

Dreger, C., Reimers, H.-E. and Roffia, B. (2007). Long-run Money Demand in the New EU Member States with Exchange Rate Effects, Eastern European Economics, 45(2), 75-94.

Engle, R.F. and Granger, C.W.J. (1987). Co-integration and Error Correction: Representation, Estimation, and Testing, Econometrica, 55, 251-76.

Favero, C.A. (2001). Applied Macroeconometrics, Oxford: Oxford University Press.

Friedman, M. (1977). Time Perspective in the Demand for Money, Scandinavian Journal of Economics, 79, 377-416.

Goldfeld, S.M. and Sichel, D.E. (1990). The Demand for Money. B.M. Friedman and F.H. Hahn (Eds), Handbook of Monetary Economics 1 (300-56).

Göktaş, Ö. (2005). Teorik ve Uygulamalı Zaman Serileri Analizi, İstanbul: Beşir Kitabevi.

https://evds2.tcmb.gov.tr, erişim tarihi: 28.01.2019.

https://www.sbb.gov.tr/, erişim tarihi: 28.01.2019.

Jawadi, F. and Sousa, R.M. (2013). Modeling Money Demand: Further Evidence from an International Perspective, Applied Economics Letters. 20(11), 1052-055.

Johansen, S. (1995). Likelihood-based Inference in Cointegrated Vector Autoregressive Models, Oxford: Oxford University Press.

Kim, S. and Subramanian, C. (2009). Velocity of Money and Inflation Dynamics, Applied Economics Letters, 16(18), 1777-781.

Laidler, E.W.D. (1993). The Demand for Money: Theories, Evidence and Problems, 4th ed. New York: Harper Collins College Publishers.

Lee, C.-C. and Chien, M.-S. (2008). Stability of Money Demand Function Revisited in China, Applied Economics. 40(24), 3185-197.

Lee, J. and Strazicich, M.C. (2003). Minimum Lagrange Multiplier Unit Root Test with Two Structural Breaks, Review of Economics and Statistics, 85(4), 1082-089. 
Pesaran, M.H. and Shin, Y. (1998). An Autoregressive Distributed-lag Modelling Approach to Cointegration Analysis, Econometric Society Monographs, 31, 371-413.

Pesaran, M.H, Shin, Y. and Smith, R.J. (2001). Bound Testing Approaches to the Analysis of Level Relationships, Journal of Applied Econometrics, 16, 289-326.

Ramachandran, M. (2004). Do Broad Money, Output and Prices Stand for a Stable Relationship in India?, Journal of Policy Modeling, 26, 983-1001.

Sarno, L. (1999). Adjustment Costs and Nonlinear Dynamics in the Demand for Money: Italy, 1861-1991, International Journal of Finance and Economics, 4, 155-77.

\section{SUMMARY}

Searchs for various properties of the money demand function need some theorizations in identifying the correct design of the monetary policies so as to satisfy the consistency of planned characteristics. Such an investigation will enable policy makers to form policy rules against major economic problems and keep us well-informed about the general outlook of what alternative costs against holding money tend to be mainly chosen by the economic agents. For these reasons, testing a standard money demand equation can provide policy makers with the crucial knowledge of expectations in the monetary markets.

In this paper, these issues of interest are tried to be estimated by constructing a standard money demand function for the demand deposits in the Turkish economy. The investigation period considered is 2005Q4-2018Q2 with quarterly observations following the change in the definition of money supplies announced by the Central Bank of the Republic of Turkey (CBRT). Following a conventional money demand model construction in the economics literature, the real gross domestic product is chosen to represent the scale income variable. The alternative cost variables to hold money balances are the average compound interest rate used in Treasury domestic borrowing auctions and the quarterly inflation rate based on gross domestic product deflator.

Since the vaiables used have found with different order of integration, the real money demand function is estimated by using contemporaneous autoregressive distributed lag bounds testing approach that yields the cointegrating knowledge of the variables in the narrowly defined money demand function using demand deposits in the Turkish banking system. The real income elasticity for money demand has been found as 1.92 , which is related to that the relationship between real income and real money balances tends to affect the current demand conditions in the economy through the inverse of the monetary velocity of circulation. Interest semi-elasticity and inflation semi-elasticity of real money demand have been obtained as -0.41 and -0.56 , respectively, which are also attributed to that economic agents in aggregate level accept the interest rate and inflation rate as an important alternative cost when determining the narrowly defined monetary holdings. The error correction modeling indicates that divergence from the long run money demand relationship is corrected about $16 \%$ in one period, that is, equilibrium conditions are re-established within six periods. It must be specified that there exists no diagnostic based problem in the empirical 
model, so the estimation process carried out satisfies the main statistical prerequisites.

Following these findings, in designing and implementation process of monetary policy, the estimated knowledge as for the narrowly defined monetary aggregates and the theory based relationships between these aggregates must be considered crucially by the policy makers and this knowledge must especially be related to the inflationary framework within the Turkish economy as a policy inference. 